\title{
Cell-Matrix Adhesion Process
}

National Cancer Institute

\section{Source}

National Cancer Institute. Cell-Matrix Adhesion Process. NCI Thesaurus. Code C20191.

Any cellular process in which a cell attaches to the extracellular matrix via adhesion

molecules. 